Original Research Paper

\title{
Organization Information Ecology and E-Commerce Adoption: Effect on Organizational SMEs Performance
}

\author{
Fadi Herzallah and Muriati Mukhtar \\ School of Computer Science, Faculty of Information Science and Technology, Universiti Kebangsaan Malaysia, Malaysia
}

Article history

Received: 29-09-2014

Revised: 11-03-2015

Accepted: 22-04-2015

Corresponding Author:

Fadi Herzallah

School of Computer Science,

Faculty of Information Science

and Technology, Universiti

Kebangsaan Malaysia,

Malaysia

Email: fadi.herzallah@yahoo.com

\begin{abstract}
Electronic Commerce (EC) has recently become the subject of interest of many researchers involved in behavioral and technology acceptance. EC was heavily studied in developed countries, but there are only a few narrowly focused studies on EC adoption in developing countries, especially in the context of Small and Medium Enterprises (SMEs). Previous researchers have investigated many factors that influence the adoption of EC applications, such as organizational and technological factors. However, a review of the literature showed that Organization Information Ecology (OIE), which is an important factor in the context of $\mathrm{EC}$, has not been receiving the attention it deserves in the context of EC adoption. Based on the literature review of previous studies, a model is proposed to reviews and attempts to identify the organizational, technological and OIE factors that effect on the adoption of EC and the impact of EC on organization performance. Altogether, twelve hypotheses are proposed. The proposed conceptual model provides a foundation for test the relationships in our suggested model by using the empirical data or other techniques.
\end{abstract}

Keywords: EC, Adoption, Organization Information Ecology, Developing Countries, Small and Medium Enterprises (SMEs)

\section{Introduction}

Rapid and permanent development of technology has opened new frontiers and possibilities for organizations (Kolarić et al., 2011). The idea of conducting business transactions via electronic media, rather than face-toface, has been discussed for decades (Van Slyke and Belanger, 2002). However, the term Electronic Commerce (EC) has only appeared as an important topic in literature, especially for business and academic research more recently, ever since the early 1990s when the Internet started to have commercial use.

EC is said to be replacing the traditional business practices. Many studies confirm that everywhere businesses significantly and positively affected by EC (Daniel, 2003; Brown and Lockett, 2004; Pool et al., 2006). EC began in 1994 and it is a process of purchasing, selling, transferring, or exchanging goods, services and information via the Internet (Mohammed et al., 2013). Companies have utilized the Internet for managing the information and integrating EC into their reengineered business processes. Clearly, EC has created favorable conditions for economies to change their paradigm from the labor-intensive to a knowledge-worker that has high possibility to be more important and dominant factor in the future. There are many benefits for companies that adopted EC in their operations, such as reduction in costs of doing business, improved product/service quality, new customer and supplier penetration and generation of new ways or channels for product distribution (Pham et al., 2011). These benefits are applicable for both SMEs and large firms (Pham et al., 2011). Adoption of technology and its aspects was the main focus of academicians and practitioners. However, some studies focus on the adoption and utilization of EC in SMEs (Pham and Nguyen, 2010; Ghobakhloo et al., 2011; Maryeni et al., 2012; Mohammed et al., 2013; Hashim and Noor, 2014). Everybody will accept the fact that SMEs are important factor for the economy in both developed and developing countries. It should also be pointed out that EC can create different potential advantages, but the adoption of EC by SMEs' is still limited, because SMEs and large enterprises are significantly different. 
SMEs are vital for the economic growth in the developed and developing world. It is estimated that more than $80 \%$ of the global economic growth comes from SMEs (Mohammed et al., 2013). Moreover, there are many studies related to the adoption of EC solutions by SMEs (Molla and Licker, 2005; Tan et al., 2007); these studies discussed some barriers faced by SMEs during the process of implementation of EC solutions in developed economies. It is shown that SMEs' cannot improve their business operations because they are unable to take advantage of the Internet and this fact is detrimental to their development.

This paper aims to reviews and attempts to identify the organizational, technological and OIE factors that effect on the adoption of EC and the impact of EC on organization performance. Determining the factors that affect the adoption of EC is vital to ensure its success and to let the decision makers and business owners focus on these factors so that they can guarantee the feasibility of adoption and implementation of EC by SMEs. This paper consists of six sections. The first section introduces the paper. The second section reviews the literature pertaining to $\mathrm{EC}$ adoption and the factors affecting EC adoption. The third section the research methodology. The fourth section proposes the conceptual model and hypothesis of this paper. The fifth section the relation between EC adoption and organization performance. The sixth section summarized hypothesis and the final section concluding remarks.

\section{Literature Review}

\section{EC Definition}

The concept of EC has been investigated broadly and defined in different ways (Mutua and Njeru, 2013). According to literature, there are many different definitions of EC. Some researchers define EC in a very general way, stating that all business activities that are transacted electronically are regarded as EC. For example, Swatman (1996) pointed out that EC is "Any electronically-enabled business activity or process." This type of definition is simplistic, as it does not address other issues pertaining to the subject.

Other definitions limit a link the EC activities to the Internet. For example Schneider (2006), defined EC as "All businesses activities that use Internet technologies". This definition failed to account for the fact that EC was launched before the Internet in the 1970s. Other researchers, however, took this into account and posited that EC is applicable via networks, including the Internet. For example, Turban et al. (2008) define EC as "the process of buying, selling, transferring, or exchanging products, services and/or information via computer networks, including the Internet". In conclusion, this paper treats EC as, "any economic or business activity that uses Information Communication Technology (ICT) based on applications to enable the buying and selling of products and services and to facilitate the transaction of business activities between and among businesses, individuals, governments or other organizations" (Fink and Disterer, 2006).

\section{Types of EC}

EC is an umbrella concept that integrates different types of existing and new applications (Kalakota and Whinston, 1996). There are five major types of EC:

- Business-to-Consumer EC (B2C), where online business attempts to reach individual consumers

- Business-to-Business EC (B2B), where the focus of the business is to sell to other businesses. They stated that Business-to-Government (B2G) is a subset of Business-to-Business EC (B2B)

- Consumer-to-Consumer EC $(\mathrm{C} 2 \mathrm{C})$, provides a way for consumers to sell to each other, with the help of an online market maker such as the auction site

- Peer-to-Peer EC (P2P), which enable Internet users to share files and computer resources directly without having to go through a central web server

- Mobile EC (m-commerce), which is the use of mobile phones to complete transactions using text messages or data via a public or private network

Three of these types of ECs are based on the market relationship, which means who is seller and who is customer (Laudon and Traver, 2009). The other two Peer-to-Peer (P2P) and mobile commerce (Mcommerce), are technology-based distinctions.

\section{Reasons for Adoption of EC}

The improvement in global communications has led companies around the world to shift towards EC (Barbonis and Laspita, 2005). Chong et al. (2009) identified some factors affecting collaborative commerce (c-commerce) adoption by Malaysian organizations. These factors included competitive pressure and top management support. Jianhong and Hua (2011) pointed out that consumer belief is a significant factor affecting the adoption of EC. Consumer belief is affected by many factors, such as privacy, trust, economic conditions, social culture and suppliers' reputations. Chan et al. (2001) identified a number of key drivers that encourage suppliers to implement EC:

- Internet makes distribution systems simpler for firms

- The increasing competition in business forces companies to search for new opportunities, such as implementing EC in their businesses 
- Globalization leads companies to move into international markets to expand their networks

- The information age, where businesses increase their trade through benefiting from collecting information for marketing purposes

- The use of technologies for automation to avoid the increasing cost of labour

Finally, to satisfy companies and customers' requirements, there should be low cost and high quality products and services. The research conducted in Turkey by Aydemir (2013) reveals that the benefits that can be gained through EC adoption are: access to new markets, enhance competitiveness and cost advantage. Wanyoike et al. (2012) determined that the advantages of using the EC are simplification of work, reliable communication, improved customer satisfaction, new product and services, reduction of cost and increased productivity, while Olatokun and Kebonye (2010) found the major reasons for EC technology adoption is competitive advantage and customers and suppliers' pressures.

Al-Abdallah (2013) has shown that one of the benefits of EC adoption is customer loyalty, while customer retention and attracting new customers weakly contributed to EC adoption. April and Pather (2008) found that one of the benefit of EC adoption is enhancing service quality. Daniel et al. (2002) classified SMEs that adopt EC into four stages:

- Developers: Creating their first e-mail and website

- Communicators: Communication with customers and suppliers through e-mail by exchanging documents and designs;

- Web presence: Those that have websites for online shopping with ordering facilities

- Transactors: Those that have websites for online shopping with ordering and payment facilities

But, this classification into stages was criticised as the firms are capable of leapfrogging the stages. AlQirim (2003) identified the levels of national infrastructure and government involvement in fostering EC adoption as other important factors, which need to be accounted for by policy makers.

\section{EC Adoption Barriers}

Ghobakhloo et al. (2011) cited that in developing countries some factors, such as the quality, availability and cost of access to necessary infrastructure negatively affected EC adoption, while in developed countries the infrastructure for EC initiatives is well-developed, accessible and affordable. Tan et al. (2007) noticed the challenges that affect SMEs in developing and developed countries are very different, so the degree of adoption and expected benefits are also different. This can be the result of the socio-cultural differences between them.

Khalifa et al. (1999) showed that one of the biggest barriers to the adoption of ICT is perceived or real risk, such as breakdown of IT infrastructure, the loss of data and uncertainties. They stated that the main elements related to EC are security, authentication, privacy and legal issues. According to Kalakota and Robinson (2001) resistance of managers to take the responsibility for technological change is the main barrier to EC adoption. Limthongchai and Speece (2003) discovered that one of the main barriers in developing EC is its associated security. This is especially poignant to companies; information security is their utmost concern vis-à-vis the adoption of EC.

Aydemir (2013) in his paper, found that the barriers for EC adoption in Turkey were related to the acceptability within the sector, customers' preferences, security issue, inadequate technical infrastructure, cost and the lack of competence in EC. The barriers to EC are inadequate infrastructure, limited capital and reliability of customers and training problems. Stockdale and Standing (2004) divided the barriers of EC adoption into internal and external barriers. The internal barriers are: identification of benefits, global trading, financial constraints, supply chain integration and understanding e-environment, while the external barriers are the lack of understanding of SMEs' needs, no common technology standard and the e-competences of industry sector. Petrović and Kovačević (2012) found that distrust is one of the main direct reasons for low level of EC adoption. The study suggested fundamental changes for the purpose of wider adoption of EC. Ramsey et al. (2008) found the differences between adopters and non-adopters are ECs' capability and willingness to change/rate of response to new technologies.

\section{Related Work}

Faloye (2014) conducted study in the South Western part of Nigeria to identify the factors that affect ecommerce adoption by Small Scale Enterprises (SSEs) in there retail sector. The data for this study were derived from completed questionnaires collected from the owners of 228 SSEs selected for the study. The data collected were analyzed using descriptive statistics. The study reveals that the majority of the SSE owners in the study area have yet to adopt e-commerce. Moreover, those that have adopted it are in the early stages of ecommerce. Moreover, the study shows that retail SSEs' online sale is virtually zero. The study concluded that despite high computer literacy level and personal computer usage among the SSE owners, the extent of ecommerce adoption in Nigeria's retail sector is quite low. Moreover, e-commerce among retail SSEs is at the rudimentary level, because findings revealed that the most common e-Commerce applications are e-mails and 
SMS via their mobile phones, used to communicate with customers and suppliers.

In Malaysia, Hashim and Noor (2014) found that there are two important factors that prompt SMEs to adopt e-commerce: its location and the managers' experience of living abroad. To encourage the adoption of e-commerce, SMEs in developing countries need not only possess the appropriate technological infrastructure installed, but they also have to be in a location that has access to good public transportation services and efficient delivery methods. The manager is also required to have experience in commerce over the Internet, which is expected of managers who have previously lived abroad.

Oreku et al. (2013) in their study help identify the important factors in the implementation of EC. However, the study was located in East Africa, which differs culturally from the Middle East. Most of researchers supposed that culture, economic conditions, consumer behavior and purchasing power parity are the factors that have a direct impact on the implementation of ecommerce. As there are substantial differences between East Africa and the Middle East with regards to economic, social and cultural parameters, its findings may not be applicable elsewhere.

Al-Hudhaif and Alkubeyyer (2011) investigated the factors affecting the implementation of e-commerce in the Kingdom of Saudi Arabia. However, the study does focus on the holistic view of the e-commerce adoption.

In a similar approach to Lip-Sam and Hock-Eam (2011), Bahaddad et al. (2012) tested 17 factors under three categorizations, namely, people and organization, technological and environmental and traditions and culture. The study reveals that only 9 factors are significant. Under people and organizational group, the significant factors are: Good previous IT experiences, educational background, lack of resource and IT skills and lack of interest and awareness. Under the technological and environmental group: E-mall website characteristics and its security, safe payment methods and delivery system. Under traditional and cultural group, the significant factors are telecommunication and logistical infrastructures.

Other researchers identify and test the factors that have impact on the implementation of e-commerce in the context of SMEs. In Malaysia, the factors that affect adoption were found to be relative advantage, compatibility, organizational readiness, manager's characteristic and security (Shah Alam et al., 2011). In North American firms, Sila (2013) found that firm size, firm type, management level of respondents and country of origin of firms have impact on EC adoption.
In Jordan, Al-Weshah and Al-Zubi (2012) found the factors to be top management support, followed by business partners. In the UK, a study by Wilson et al. (2008) utilized quantitative approach by distributing questionnaires to $678 \mathrm{SMEs}$ and found the factors to be top management support, management understanding and presence of IT skills, availability of consultancy and prioritization of e-commerce, compared with other projects. Wanyoike et al. (2012) agreed with Shah Alam et al. (2011) and they stated that the reason behind the adoption of e-commerce is only relative advantages and observability.

Saffu et al. (2012) found that perceived usefulness, ease of use, readiness and compatibility and external pressure, respectively, in order of importance, were the factors affecting the adoption of e-commerce. The findings of an Irish study by Ramsey et al. (2008) reveal that there are seven factors that can induce companies in Ireland to adopt e-commerce, which are "e-commerce capability", "willingness to change/rate of response to new technologies", "technological opportunity recognition", "customer orientation", "sensitivity to competitive/customer environment", "perception of technology feasibility" and "e-skills development mechanisms".

Similarly to Shah Alam et al. (2011), Ifinedo (2011) found that relative advantages have the strongest impact on the adoption of SMEs in Canada, followed by the competition's pressure and management support, respectively, which differs from the finding of AlWeshah and Al-Zubi (2012; Ifinedo, 2011), who found that business partners, along with compatibility and complexity and government support were not significant for the adoption of SMEs. In contrast with Ifinedo (2011), Zakaria and Janom (2011) found that government support, along with other factors such as personal traits dimension, enterprise readiness, competency of staff and organization, technology, business process and market forces are factors that can affect the smooth implementation of e-commerce

\section{Research Methodology}

This research paper aims to reviews and attempts to identify the organizational, technological and OIE factors that effect on the adoption of EC and the impact of EC on organization performance. This paper using quantitative approach. An intensive literature review is conducted to extract the most significant mentioned factors that affect the adoption of EC by SME.

\section{Proposed Model and Hypotheses Argument}

EC technology is rapidly increasing in global businesses. However, the literature on EC is still 
disjointed and confusing from an organizational perspective, particularly on the adoption and business performance. Thus, there is a need to develop an integrated conceptual model, combined with theories and critical factors. The combination of organizational perspectives, technology perspectives and organization information ecology perspectives leads to the development of a comprehensive and multidimensional conceptual model. This model in the Fig. 1 will be used in the current paper to examine the impact of EC adoption on organizational performance as well. The development of the different hypothesis and the direction of their effect on EC adoption are shown in Table 1.

This paper observed most of the main critical factors described in the literature related to EC and technology adoption. On top of the organizational, technology and Organization information ecology perspectives, the current paper also includes the organization performance scorecard for a comprehensive and multidimensional research model.

\section{Organizational Perspectives}

This aspect can be regarded as having a powerful effect on the implementation of EC by SME. Factors in the organizational context are the main objectives of many studies related to SMEs (Premkumar, 2003). Information intensity, CEO's IS Knowledge, COE's innovations, business size are considered to be organizational factors that affect the SMEs' adoption of

EC.

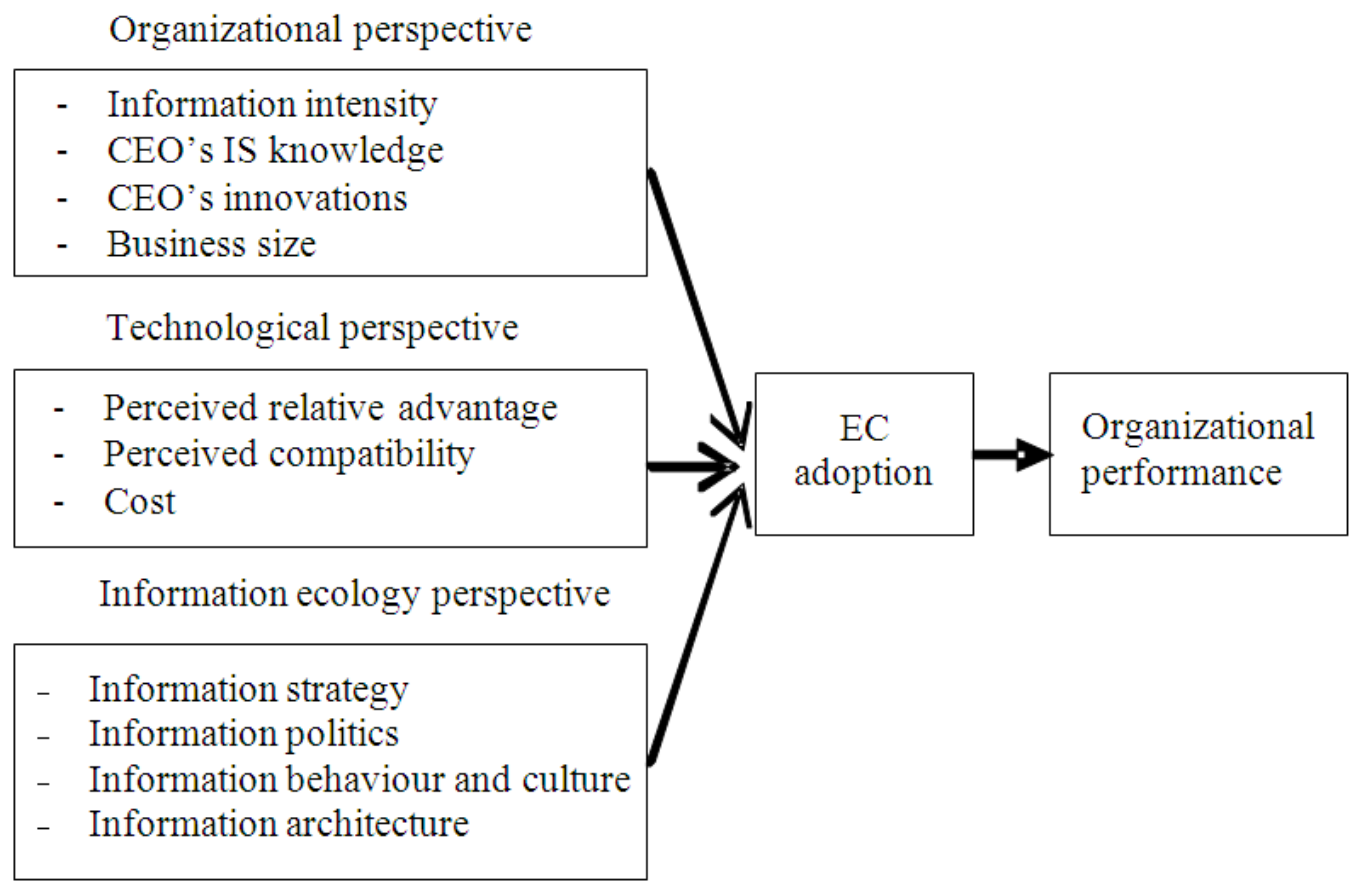

Fig. 1. Proposed conceptual model

Table 1. Research hypothesis

\begin{tabular}{ll}
\hline H1 & There is a positive relationship between Information intensity of environment and EC adoption by SME's \\
H2 & There is a positive relationship between CEO's IS knowledge and EC adoption by SME's \\
H3 & There is a positive relationship between CEO's innovativeness and EC adoption by SME's \\
H4 & There is a negative relationship between business size and EC adoption by SME's \\
H5 & There is a positive relationship between perceived relative advantage and EC adoption by SME's \\
H6 & There is a positive relationship between compatibility and EC adoption by SME's \\
H7 & There is a negative relationship between cost and EC adoption by SME's \\
H8 & There is a positive relationship between well-defined organizational information strategy and EC adoption by SME's \\
H9 & There is a positive relationship between well-defined organizational information politics and EC adoption by SME's \\
H10 & There is a positive relationship between well-defined organizational information behaviour, culture and EC adoption by SME's \\
H11 & There is a positive relationship between well-defined organizational information architecture and EC adoption by SME's \\
H12 & There is a positive relationship between E-commerce adoption and organizational performance \\
\hline
\end{tabular}




\section{Information Intensity and EC Adoption}

The literature related to information systems recommends that the rationale for the adoption of information systems (EC applications) by SMEs is to deal with the experienced information intensity (Al-Qirim, 2007). Information intensity is the extension of available information to the business according to its products and services. Since firms in specialized business sectors have different information processing requirements, companies related to Information-intensive industries are more intended to adopt information systems (Thong and Yap, 1995). Information processing requirements stem from internal and environmental confusions (Anandarajan and Arinze, 1998). Investment on more developed information systems has aim to increase information processing capacity and flexibility, so as businesses can efficaciously sustain and manage uncertainties and promote decision-making (Karimi et al., 2004). So, it could be implied that firms that have high information processing requirements and are active in intensive information usage environment, are more intended to adopt and use information system innovations (Ghobakhloo et al., 2011; Aziz and Jamali, 2013). Thus, the following hypothesis is posited:

H1: There is a Positive relationship between Information intensity of environment and EC adoption by SME's.

\section{CEO's IS knowledge and EC Adoption}

The knowledge of Chief Executive Officer (CEO) on Information System (IS) is another factor that affects the adoption of IS (Fink, 1998). According to the idea of "knowledge barriers" defined by Attewell (1992), "user skill and knowledge development can facilitate and speed up the adoption of new technologies, such as IS". Due to their inadequate knowledge of information systems SMEs can face serious risks and problems related to their computerization (Caldeira and Ward, 2003). So, the degree of uncertainty associated with IS adoption will be less with sufficient knowledge of CEOs, which will lead to the lower risk of IS adoption. Similarly, another determinant of EC applications adoption attributable to the characteristics of top management is CEO innovativeness (Lee, 2004). Thus, the following hypothesis is posited:

H2: There is a Positive relationship between CEO's IS knowledge and EC adoption by SME's.

\section{CEO's Innovativeness and EC Adoption}

It was revealed that small companies with innovative CEO's have more chances to progress toward IS adoption (Fink, 1998). Some studies (Ghobakhloo et al., 2011; Araste et al., 2013; Aziz and Jamali, 2013) found that CEO innovativeness will positively affect the implementation of EC by the SME segment. Specific and risky solutions such as information systems are preferable for innovative CEOs to modify the structure with generated problems. Therefore, CEO innovativeness will hasten the process of information systems implementation (Thong and Yap, 1995). Thus, the following hypothesis is suggested:

H3: There is a Positive relationship between CEO's innovativeness and EC adoption by SME's.

\section{Business Size and EC Adoption}

Previous literature on information systems implementation within SMEs supposed that the size of a business is one of the most significant determinants of information systems implementation which can be defined by turnover and/or number of employees (Premkumar and Roberts, 1999; Love et al., 2005). The significance of firm size is important factor that plays specific role as the source of firm's capabilities and firm's resources, including financial and human capital (Mole et al., 2004). It is shown that in small business groups larger firms compare to small firms are more intended to communication technologies implementation (Premkumar and Roberts, 1999; Premkumar, 2003). Likewise, in SME business group larger businesses that have more resources are inclined to adopt a more developed form of information systems (Thong, 1999). It was also proposed that business size is an important factor for the adoption or non-adoption of EC applications (Al-Qirim, 2007). Thus, the following hypothesis is suggested:

H4: There is a negative relationship between Business size and EC adoption by SME's.

\section{Technology Perspectives}

This factor can be considered as an important one that have a powerful effect on EC implementation by SMEs (Davis, 1989; Premkumar, 2003). Very few studies have investigated the effect of technological characteristics on ICT implementation by SMEs. Perceived relative advantage, perceived compatibility and costs are important factors that affect the SMEs' adoption of EC.

\section{Perceived Relative Advantage and EC Adoption}

Perceived relative advantage (or perceived benefits) is the view that definite benefits will be gained by the behavior performance. It is one of the characteristics that frequently used in the studies related to EC adoption (Kuan and Chau, 2001; Seyal et al., 2004). Most studies found out that perceived relative advantage is a significant factor for the adoption of information technologies (Kaynak et al., 2005; Al-Qirim, 2007; Ahmad et al., 2014). Many studies have stated that the implementation of e-commerce affects an organization's 
performance, especially growth, (Raymond et al., 2005; Qureshi et al., 2010), financial gain (Johnston et al., 2007) and competitive advantage (Teo, 2007). Thus, the following hypothesis is suggested:

H5: There is a Positive relationship between Perceived relative advantage and EC adoption by SME's.

\section{Perceived Compatibility and EC Adoption}

Perceived compatibility refers to the compatibility between e-commerce and the current business processes (i.e., suppliers and customers). Grandon and Pearson (2004) considered this compatibility as an important factor in determining adoption. Some studies related to the implementation of EC adoption within SMEs showed significant effect of EC compatibility on e-commerce adoption and usage (Hong and Zhu, 2006; Saffu et al., 2008; Ahmad et al., 2014). Therefore, organizational compatibility deficiency may cause constraints on the level of used EC (Gibbs and Kraemer, 2004). Thus, the following hypothesis is suggested:

H6: There is a Positive relationship between Compatibility and EC adoption by SME's.

\section{Cost and EC Adoption}

The costs of information systems adoption is one of the important technological factors that have impact on the implementation of EC by SMEs (Tan et al., 2009). Lack of financial resources enforces SMEs to be careful about their investment and capital spending, thus; only for SMEs with suitable financial resources the adoption of information systems can be considered as an executable project (Thong and Yap, 1995). Indirect costs of information systems implementation (human factors (e.g., training) and early cost of temporary loss in firm's productivity) also affect IS adoption (Love and Irani, 2004) and may higher impact than direct costs (Love et al., 2005). Consequently, total costs of EC development can be an important influential factor of EC adoption. Hence, the following hypotheses are stated:

H7: There is a negative relationship between Cost and EC adoption by SME's.

\section{Organization Information Ecology Perspectives}

Another factor that may affect EC initiatives and plans is an organization's information ecology (Detlor, 2001). The organization information ecology construct refers to "the internal information environment within the firm, comprising of many interdependent social and cultural systems, which affect the creation, distribution and use of information" (Davenport and Prusak, 1997). Nardi and O'Day (1999) proposed that information sharing, reduce information overload, promote a positive attitude towards the use of information are the factors, that can be facilitated by organizations with "healthy information ecologies". Davenport and Prusak (1997) recommend organizations to be cautious about their internal information environments, because it can facilitate information management. Davenport's model based on the context of information ecology within organization. Davenport differentiates several components of information ecology within organization, which are information strategy, information politics, information behaviour and culture and information architecture.

\section{Information Strategy and EC Adoption}

Information Strategy is a comprehensive strategy related to information management which is the best support for the goals and strategies of the business (Howard, 2008). Information strategy also related to making choices, not carving out a master plan set in stone. "Ecologically minded managers will strategize about which information to focus on, what information activities to emphasize and how information will help their organization meet its objectives" (Davenport and Prusak, 1997). Consequently, Information Strategy will not be related just to technology and tools, it will also include people and organization. Hence, the following hypotheses are stated:

H8: There is a positive relationship between welldefined organizational information strategy and EC adoption by SME's.

\section{Information Politics and EC Adoption}

Information politics is defined as the usage of power derived from information and its responsible use (Davenport and Prusak, 1997). Information is influenced by power, politics and economics on a frequent basis in all organizations. However, it is well known that many managers try to actively avoid dealing with information politics, as it is assumed to undercut an organization's hierarchy. Therefore, power plays or political wrangling over information when they do muscle themselves into managerial awareness have been treated as an aberration rather than as a natural and necessary component of information management and the all-important economic ramifications of information politics are often dismissed, since it's hard to quantify information value. Hence, the following hypotheses are stated:

H9: There is a positive relationship between welldefined organizational information politics and EC adoption by SME's.

\section{Information Behaviour, Culture and EC Adoption}

Information behavior it is personal approach of individual to handle, to search, to use, to modify, to share, to hoard and even to ignore the information. Consequently, handling information behavior implies that we are attempting to increase the effectiveness of information environment within organization via 
concerted action (Davenport and Prusak, 1997). Information culture includes a firm's information behavior and specifies "how much those involved value information, share it across organizational boundaries, disclose it internally and externally and capitalize on it in their businesses" (Davenport and Prusak, 1997). Thus, the following hypothesis is suggested:

H10: There is a positive relationship between welldefined organizational information Behaviour, Culture and EC adoption by SME's.

\section{Information Architecture and EC Adoption}

Information architecture, is simply a set of supports by which the information needs and information resources can be matched (Davenport and Prusak, 1997). A well-designed architectural approach arranges information within organization by the help of certain formats, categories and relationships. From the perspective of information ecology, architecture includes engineer models and maps, directories and standards. These aids may be automated, document-based, or in the mind of a single expert. Thus, the following hypothesis is suggested:

H11: There is a positive relationship between welldefined organizational information architecture and EC adoption by SME's.

\section{EC Adoption and Organizational Performance}

An organization performance is a significant business result measured according to its planned outputs. This factor is affected by the development of information and communication technologies and faces changes in business environment. The enhancement of the organization performance is based on the rising development of ICT. Organizational performance is obtaining exceptional improvement from the growth of information and communication technologies in business and trade (Jahanshahi et al., 2012). In this study, we have targeted the effect of the EC adoption on the organizations performance. Thus, the following hypothesis is suggested:

H12: There is a positive relationship between Ecommerce adoption and organizational performance.

\section{Summarized Hypothesis}

The development of the different hypothesis and the direction of their effect on EC adoption are shown in Table 1.

\section{Concluding Remarks}

This research contributes to both academic research and management practice, as it provide a theoretically comprehensive influence on the adoption of EC on organization performance. This paper proposed a conceptual model that includes multidimensional perspectives in investigating the adoption of $\mathrm{EC}$ and its effect on organizational performance. These multidimensional perspectives are namely, organizational, technological and organization information ecology. This paper contributes a useful guide for the companies that have already implemented EC technology in their businesses to estimate their EC strategies and development and to identify the areas that need to be revised in the context of taking potential feedback from their EC investments. Besides, this paper also inspires the non-adopter of EC technology to embark their organizations into e-commerce. The opportunities for future research for this paper should continue the empirical research by validate the model by conducting a quantitative study on ICT based SMEs in Palestine. Based on the analyses and opinion of those SMEs, the model will be further modified. The other, to consider in some variable factors that can be adopted for future studies for test the other dimensions and the study should be able to replicate the process in other type of ecommerce such as B2B, B2C. Finally, we encourage this research work will be more beneficial if it is expanded in the future to test the relationships in our suggested model by using the empirical data or other techniques.

\section{Acknowledgement}

The researchers would like to thank National University of Malaysia for financial support. Many thanks to the Reviewers for their constructive comments.

\section{Author's Contributions}

All authors equally contributed in this work.

\section{Ethics}

This article is original and contains unpublished material. The corresponding author confirms that all of the other authors have read and approved the manuscript and no ethical issues involved.

\section{References}

Ahmad, S.Z., A.R. Abu Bakar, T.M. Faziharudean and K.A. Mohamad Zaki, 2014. An empirical study of factors affecting e-commerce adoption among small-and medium-sized enterprises in a developing country: Evidence from Malaysia. Informa. Technolo. Development. DOI: $10.1080 / 02681102.2014 .899961$

Al-Abdallah, G.M., 2013. The effect of customercompany relationship on internet adoption in Jordanian small and medium enterprises. J. Econ. Behav. Stud., 5: 192-199. 
Al-Hudhaif, S.A. and A. Alkubeyyer, 2011. E-commerce adoption factors in Saudi Arabia. Int. J. Bus. Manage., 6: 1833-8119.

DOI: $10.5539 /$ ijbm.v6n9p122

Al-Qirim, N., 2007. The adoption of e-commerce communications and applications technologies in small businesses in New Zealand. Electr. Commerce Res. Applic., 6: 462-473.

DOI: $10.1016 /$ j.elerap.2007.02.012

Al-Qirim, N.A.Y., 2003. E-commerce in the aerial mapping industry: A New Zealand case study. J. Syst. Inform. Technol., 7: 67-92. DOI: $10.1108 / 13287260380000774$

Al-Weshah, G.A. and K. Al-Zubi, 2012. E-business enablers and barriers: Empirical study of SMEs in Jordanian communication sector. Global J. Bus. Res., 6: 1-15.

Anandarajan, M. and B. Arinze, 1998. Matching client/server processing architectures with information processing requirements: A contingency study. Inform. Manage., 34: 265-274.

DOI: $10.1016 / \mathrm{S} 0378-7206(98) 00064-0$

April, G.D. and S. Pather, 2008. Evaluating service quality dimensions within e-commerce SMEs. Electronic J. Informa. Syst. Evaluat., 11: 109-124.

Araste, A.R., A. Mansouri and M. Jafari, 2013. The factors affecting the e-commerce adoption in SMEs in the industrial towns of Zanjan-Iran: Managers` perspectives. Int. J. Acad. Res. Bus. Soc. Sci., 3: 100-109. DOI: 10.6007/IJARBSS/v3-i10/280

Attewell, P., 1992. Technology diffusion and organizational learning: The case of business computing. Organ. Sci., 3: 1-19.

DOI: 10.1287 /orsc.3.1.1

Aydemir, C., 2013. A survey aimed at E-commerce applications in firms operating in Diyarbakir organised industrial Zone. Int. J. Bus. Soc. Sci., 4: 59-59.

Aziz, F.A. and N. Jamali, 2013. Factors inflencing the level of adoption in electronic commerce among SMEs. Inter. J. Inform. Technol. Comput. Sci., 8: 105-110.

Bahaddad, A.A., R. AlGhamdi and L. Houghton, 2012. To what extent would e-mall enable SMEs to adopt e-commerce? Int. J. Bus. Manage., 7: 123-132. DOI: 10.5539/ijbm.v7n22p123

Barbonis, P.A. and S. Laspita, 2005. Some factors influencing adoption of e-commerce in Greece. Proceedings of the IEEE International Engineering Management Conference, Sept. 11-13, IEEE Xplore Press, pp: 31-35.

DOI: 10.1109/IEMC.2005.1559082

Brown, D.H. and N. Lockett, 2004. Potential of critical eapplications for engaging SMEs in e-business: A provider perspective. Eur. J. Inform. Syst., 13: 21-34. DOI: 10.1057 /palgrave.ejis. 3000480
Caldeira, M.M. and J.M. Ward, 2003. Using resourcebased theory to interpret the successful adoption and use of information systems and technology in manufacturing small and medium-sized enterprises. Eur. J. Inform. Syst., 12: 127-141.

DOI: 10.1057 /palgrave.ejis.3000454

Chan, H., E. Chang, T. Dillon and R. Lee, 2001. ECommerce: Fundamentals and Applications. 1st Edn., Wiley, New York, SBN-10: 0471493031, pp: 504.

Chong, A.Y.L., K.B. Ooi, B. Lin and M. Raman, 2009. Factors affecting the adoption level of ccommerce: An empirical study. J. Comp. Inform. Syst., 50: 13-22.

Daniel, E., 2003. An exploration of the inside-out model: E-commerce integration in UK SMEs. J. Small Bus. Enterprise Dev., 10: 233-249. DOI: $10.1108 / 14626000310489691$

Daniel, E., H. Wilson and A. Myers, 2002. Adoption of E-Commerce by SMEs in the UK towards a stage model. Int. Small Bus. J., 20: 253-270. DOI: $10.1108 / 14626000310489691$

Davenport, T.H. and L. Prusak, 1997. Information Ecology: Mastering the Information and Knowledge Environment. 1st Edn., Oxford University Press, New York, ISBN-10: 0198027184, pp:272

Davis, F.D., 1989. Perceived usefulness, perceived ease of use and user acceptance of information technology. MIS Q., 13: 319-340. DOI: $10.2307 / 249008$

Detlor, B., 2001. The influence of information ecology on e-commerce initiatives. Internet Res., 11: 286-295. DOI: $10.1108 / 10662240110402740$

Faloye, D.O., 2014. The adoption of e-commerce in small businesses: An empirical evidence from retail sector in Nigeria. J. Bus. Retail Manage. Res., 8: 54-64.

Fink, D. and G. Disterer, 2006. International case studies: To what extent is ICT infused into the operations of SMEs? J. Enterprise Inform. Manage., 19: 608-624. DOI: 10.1108/17410390610708490

Fink, D., 1998. Guidelines for the successful adoption of information technology in small and medium enterprises. Int. J. Inform. Manage., 18: 243-253. DOI: $10.1016 / \mathrm{S} 0268-4012(98) 00013-9$

Ghobakhloo, M., D. Arias-Aranda and J. BenitezAmado, 2011. Adoption of e-commerce applications in SMEs. Industrial Manage. Data Syst., 111: 1238-1269. DOI: $10.1108 / 02635571111170785$

Gibbs, J.L. and K.L. Kraemer, 2004. A cross country investigation of the determinants of scope of Ecommerce use: An institutional approach. Elect. Markets, 14: 124-137. DOI: $10.1080 / 10196780410001675077$

Grandon, E.E. and J.M. Pearson, 2004. Electronic commerce adoption: An empirical study of small and medium US businesses. Inform. Manage., 42: 197-216. DOI:10.1016/j.im.2003.12.010 
Hashim, N.A. and S.M. Noor, 2014. An Investigation of Key Adoption of E-Commerce in SMEs in Malaysia. Proceedings of the 26th International Business Research Conference. April 7-8, Imperial College, London, UK, pp: 1-17.

Hong, W. and K. Zhu, 2006. Migrating to internet-based e-commerce: Factors affecting e-commerce adoption and migration at the firm level. Inform. Manage., 43: 204-221. DOI: 10.1016/j.im.2005.06.003

Howard, P., 2008. The importance of an information strategy. IBM.

Ifinedo, P., 2011. An empirical analysis of factors influencing internet/e-business technologies adoption by SMEs in Canada. Int. J. Inform. Technol. Decision Making, 10: 731-766. DOI: $10.1142 / \mathrm{S} 0219622011004543$

Jahanshahi, A.A., M. Rezaei, K. Nawaser, V. Ranjbar and B.K. Pitamber, 2012. Analyzing the effects of electronic commerce on organizational performance: Evidence from small and medium enterprises. Afr. J. Bus. Manage., 6: 6486-6496. DOI: $10.5897 /$ AJBM1 1.1768

Jianhong, H. and L. Hua, 2011. A research on consumers' adopting motives of e-commerce. Proceedings of the International Conference on Management Science and Industrial Engineering, Jan. 8-11, IEEE Xplore Press, Harbin, pp: 158-161. DOI: 10.1109/MSIE.2011.5707686

Johnston, D.A., M. Wade and R. McClean, 2007. Does e-business matter to SMEs? A comparison of the financial impacts of internet business solutions on European and North American SMEs. J. Small Bus. Manage., 45: 354-361. DOI: 10.1111/j.1540-627X.2007.00217.x

Kalakota, R. and A.B. Whinston, 1996. Frontiers of Electronic Commerce. 1st Edn., Addison Wesley Longman Publishing Co., Inc. Redwood City, CA, USA, ISBN-10: 0-201-84520-2, pp: 850.

Kalakota, R. and M. Robinson, 2001. E-business 2.0: Roadmap for Success. 1st Edn., Addison-Wesley Professional, Harlow, ISBN-10: 0201721651, pp: 520.

Karimi, J., T.M. Somersa and Y.P. Gupta, 2004. Impact of environmental uncertainty and task characteristics on user satisfaction with data. Inform. Syst. Res., 15: 175-193. DOI: $10.1287 /$ isre. 1040.0022

Kaynak, E., E. Tatoglu and V. Kula, 2005. An analysis of the factors affecting the adoption of electronic commerce by SMEs: Evidence from an emerging market. Int. Mark. Rev., 22: 623-640.

DOI: $10.1108 / 02651330510630258$

Khalifa, G., Z. Irani and L. Baldwin, 1999. Factors Impacting IT/IS investment adoption and exploitation: Conceptual model. Proceedings of the 6th European IT Evaluation Conference, (EC' 99), Brunel University, UK.
Kolarić, B., R. Petrović and S. Radojčić, 2011. Application of e-business in modern operation of public companies in Serbia. Int. J. Admin., 2: 32-32. DOI: 10.5430/ijba.v2n3p32

Kuan, K.K. and P.Y. Chau, 2001. A perception-based model for EDI adoption in small businesses using a technology-organization-environment framework. Inform. Manage., 38: 507-521. DOI: $10.1016 / \mathrm{S} 0378-7206(01) 00073-8$

Laudon, K.C. and C.G. Traver, 2009. E-CommerceBusiness, Technology, Society. 4th Edn., Pearson Addison-Wesley, Boston.

Lee, J., 2004. Discriminant analysis of technology adoption behavior: A case of internet technologies in small businesses. J. Comput. Inform. Syst., 44: 57-66.

Limthongchai, P. and M.W. Speece, 2003. The effect of perceived characteristics of innovation on ecommerce adoption by SMEs in Thailand. Proceedings of the 7th International Conference on Global Business and Economic Development, (BED' 03), Citeseer, Bangkok, Thailand, pp: 1573-1585.

Lip-Sam, T. and L. Hock-Eam, 2011. Estimating the determinants of B2B e-commerce adoption among small and medium enterprises. Int. J. Bus. Society, 12: $15-30$.

Love, P.E. and Z. Irani, 2004. An exploratory study of information technology evaluation and benefits management practices of SMEs in the construction industry. Inform. Manage., 42: 227-242. DOI: $10.1016 /$ j.im.2003.12.011

Love, P.E., Z. Irani, C. Standing, C. Lin and J.M. Burn, 2005. The enigma of evaluation: Benefits, costs and risks of IT in Australian small-medium-sized enterprises. Inform. Manage., 42: 947-964. DOI: 10.1016/j.im.2004.10.004

Maryeni, Y.Y., R. Govindaraju, B. Prihartono and I. Sudirman, 2012. Technological and organizational factors influencing the e-commerce adoption by Indonesian SMEs. Proceedings of the IEEE International Conference on Management of Innovation and Technology, Jun. 11-13, IEEE Xplore Press, Sanur Bali, pp: 436-441. DOI: 10.1109/ICMIT.2012.6225845

Mohammed, J.A., M.K. Almsafir and A.S.M. Alnaser, 2013. The factors that affects e-commerce adoption in small and medium enterprise: A review. Aus. J. Basic Applied Sci., 7: 406-412.

Mole, K.F., A. Ghobadian, N. O’Regan and J. Liu, 2004. The use and deployment of soft process technologies within UK manufacturing SMEs: An empirical assessment using logit models. J. Small Bus. Manage., 42: 303-324. DOI: 10.1111/j.1540-627X.2004.00113.x 
Molla, A. and P.S. Licker, 2005. E-commerce adoption in developing countries: A model and instrument. Inform. Manage., 42: 877-899. DOI: $10.1016 / \mathrm{j} . \mathrm{im} .2004 .09 .002$

Mutua, J., I.N. Oteyo and A.W. Njeru, 2013. The strategic value of e-commerce adoption among small and mediam enterprises in Nairobi, Kenya. Proceedings of the Mechanical Engineering Annual Conference on Sustainable Research and Innovation, (SRI' 13), pp: 133-138.

Nardi, B.A. and V. O'Day, 1999. Information Ecologies: Using Technology with Heart. 1st Edn., MIT Press, Cambridge, ISBN-10: 0262640422, pp: 232.

Olatokun, W. and M. Kebonye, 2010. E-commerce technology adoption by SMEs in Botswana. Int. J. Emerg Technol. Society, 8: 42-56.

Oreku, G.S., F.J. Mtenzi and A.D. Ali, 2013. A viewpoint of Tanzania e-commerce and implementation barriers. Comput. Sci. Inform. Syst., 10: 263-281. DOI: 10.2298/CSIS1 $10725002 \mathrm{O}$

Petrović, D. and I. Kovačević, 2012. Distrust as obstacle to e-commerce development in Serbia. Manage. J. Theory Pract. Manage., 65: 71-77.

Pham, L. and D. Nguyen, 2010. Small and medium sized enterprises' e-commerce adoption model in Vietnam. Acad. Inform. Manage. Sci., 14: 18-18

Pham, L., L.N. Pham and D. T. Nguyen, 2011. Determinants of e-commerce adoption in Vietnamese small and medium sized enterprises. Int. J. Entrepreneurship, 15: 45-72.

Pool, P.W., J.A. Parnell, J.E. Spillan and S. Carraher, 2006. Are SMEs meeting the challenge of integrating e-commerce into their businesses? A review of the development, challenges and opportunities. Int. J. Inform. Technol. Manage., 5: 97-113. DOI: 10.1504/IJITM.2006.010112

Premkumar, G. and M. Roberts, 1999. Adoption of new information technologies in rural small businesses. Omega, 27: 467-484. DOI: $10.1016 / \mathrm{S} 0305-0483(98) 00071-1$

Premkumar, G., 2003. A meta-analysis of research on information technology implementation in small business. J. Organiz. Comput. Elect. Commerce, 13:91-121. DOI: 10.1207/S15327744JOCE1302_2

Qureshi, S., P. Keen and M. Kamal, 2010. Business Models for Development: The Global Capability Sourcing Model. E-Strategies for Technological Diffusion and Adoption: National ICT Approaches for Socioeconomic Development. Sherif Kamel (Ed.,) IGI Publishing, ISBN-10: 1605663883, pp: 200-214.

Ramsey, E., P. Ibbotson and P. Mccole, 2008. Factors that impact technology innovation adoption among Irish professional service sector SMEs. Int. J. Innovation Manage., 12: 629-654.

DOI: $10.1142 / \mathrm{S} 1363919608002114$
Raymond, L., F. Bergeron and S. Blili, 2005. The assimilation of e-business in manufacturing SMEs: Determinants and effects on growth and internationalization. Electronic Markets, 15: 106-118. DOI: 10.1080/10196780500083761

Saffu, K., J.H. Walker and M. Mazurek, 2012. Perceived strategic value and e-commerce adoption among SMEs in Slovakia. J. Internet Commerce, 11: 1-23. DOI: 10.1080/15332861.2012.650986

Saffu, K., J.H. Walker and R. Hinson, 2008. Strategic value and electronic commerce adoption among small and medium-sized enterprises in a transitional economy. J. Bus. Industrial Market., 23: 395-404. DOI: $10.1108 / 08858620810894445$

Schneider, G.P., 2006. Electronic Commerce. 1st Edn., Course Technology, Boston.

Seyal, A.H., M.M. Awais, S. Shamail and A. Abbas, 2004. Determinants of electronic commerce in Pakistan: Preliminary evidence from small and medium enterprises. Electronic Markets, 14: 372-387. DOI: $10.1080 / 10196780412331311801$

Shah Alam, S., M.Y. Ali and M.F. Mohd. Jani, 2011. An empirical study of factors affecting electronic commerce adoption among SMEs in Malaysia. J. Bus. Econ. Manage., 12: 375-399. DOI: $10.3846 / 16111699.2011 .576749$

Sila, I., 2013. Factors affecting the adoption of B2B ecommerce technologies. Electronic Commerce Res., 13: 199-236. DOI: 10.1007/s10660-013-9110-7

Stockdale, R. and C. Standing, 2004. Benefits and barriers of electronic marketplace participation: An SME perspective. J. Enterprise Inform. Manage., 17: 301-311. DOI: 10.1108/17410390410548715

Swatman, P.M., 1996. Electronic commerce: Origins and future directions. Proceedings of the 1st Australian Data Administration Management Association Conference, (MAC' 96), Course Technology.

Tan, J., K. Tyler and A. Manica, 2007. Business-tobusiness adoption of e-commerce in China. Inform. Manage., 44: 332-351. DOI: $10.1016 /$ j.im.2007.04.001

Tan, K.S., S.C. Chong, B. Lin and U.C. Eze, 2009. Internet-based ICT adoption: Evidence from Malaysian SMEs. Ind. Manage. Data Syst., 109: 224-244. DOI: 10.1108/02635570910930118

Teo, T.S., 2007. Organizational characteristics, modes of internet adoption and their impact: A Singapore perspective. J. Global Inform. Manag., 15: 91-117. DOI: $10.4018 /$ jgim.2007040104

Thong, J.Y. and C.S. Yap, 1995. CEO characteristics, organizational characteristics and information technology adoption in small businesses. Omega, 23: 429-442. DOI: 10.1016/0305-0483(95)00017-I 
Thong, J.Y., 1999. An integrated model of information systems adoption in small businesses. J. Manage. Inform. Syst., 15: 187-214.

Turban, E., D. King, J. McKay, P. Marshall and J. Lee, 2008. Electronic Commerce: A managerial Perspective. 1st Edn., Prentice Hall, Oxford, OX, United Kingdom, ISBN-10: 0139752854.

Van Slyke, C. and F. Belanger, 2002. E-business technologies: Supporting the Net-enhanced Organization. John Wiley and Sons Inc, New York. ISBN-10: 0471393924.
Wanyoike, D.M., E. Mukulu and A.G. Waititu, 2012. ICT attributes as determinants of e-commerce adoption by formal small enterprises in urban Kenya. Inter. J. Bus. Soc. Sci., 3: 65-74.

Wilson, H., E. Daniel and I.A. Davies, 2008. The diffusion of e-commerce in UK SMEs. J. Market Manage., 24: 489-516. DOI: 10.1362/026725708X325968

Zakaria, M.S. and N. Janom, 2011. Developing and validating readiness measures of inter-organizational e-commerce on SMEs. J. Internet Bank Commerce, 16: 1-15. 